\title{
A ExperiênCia da Educação Profissional na Noruega.
}

\author{
Liv Mjelde
}

\begin{abstract}
Resumo
A "pedagogia da educação profissional" e a "didática da educação profissional" são novos conceitos que foram desenvolvidos para uma compreensão dos processos de ensino e aprendizagem, para os quais são centrais a aprendizagem em oficinas e a aprendizagem na vida do trabalho. A pedagogia profissional é uma abordagem do ensino e do aprendizado centrada no aluno, na qual a relação entre o estudante e a tarefa é fundamental; a própria atividade do trabalho é o fulcro da aprendizagem. Neste documento, começo analisando as maneiras de ver a unidade e as variações do desenvolvimento curricular da didática da formação profissional, trazidas pelas mudanças tecnológicas, e o desenvolvimento no mercado de trabalho e na educação profissional. Também discuto os desafios centrais de passar do aprendizado na práxis para o conhecimento geral numa variedade de áreas profissionais, nos quais o aprendizado escolar é contrastado com o aprendizado no campo de trabalho.
\end{abstract}

Palavras-chave: Educação Profissional; Pedagogia da Educação Profissional; Reforma Educacional; Noruega.

\section{INTRODUÇão}

O desenvolvimento e as mudanças no mercado de trabalho nos últimos trinta anos levaram a profundas transformações no desenvolvimento da força de trabalho, normalmente treinada em cursos profissionalizantes nas escolas profissionais ou no próprio mercado de trabalho. Na Noruega, as escolas profissionalizantes têm praticado uma divisão muito tradicional de gênero, direcionando os meninos para empregos no setor produtivo e as meninas para a esfera doméstica. No programa profissional, há recrutamento misto para alguns ofícios, como cabeleireiros, cozinheiros, garçons, fotógrafos e técnicos em prótese dentária (Mjelde, 2006). ${ }^{1}$ No entanto, as escolas profissionais para os ofícios e a indústria têm representado principalmente o mundo dos homens. Tradicionalmente, elas ofereciam à maioria das mulheres um curso de economia doméstica de meio ano, como preparação para o trabalho doméstico. Começando nos anos 1970, tivemos um impulso para direcionar as meninas para ocupações antes somente masculinas e, na década de 1980, a integração

\footnotetext{
* Dra. em Ciências Sociais, especializada em Sociologia da Educação. Prof. da Faculdade de Educaşão para Formaşão de Docentes do Ensino Profissional e Técnico da Universidade de Akershus (Noruega). Atuou como professora visitante no Instituto de Estudos em Educaşão de Ontário (OISE), na Universidade de Toronto (Canadá) e no Instituto de Educação de Adultos da Universidade de Adelaide (Austrália). Faz parte da Rede de Educação e Formação Profissional: "Vet e Cultura", desde a sua criação na Finlândia, em 1993.E-mail:LivK.Mjelde@biak.no
}

Traducão de Jones de Freitas.

Recebido para publicação em 21/06/10. das mulheres a esferas dominadas pelos homens tornou-se uma questão pública de política educacional na Noruega e em outros países escandinavos.

Vimos grandes mudanças na educação profissional por causa de transformações profundas no mercado de trabalho. As tarefas que eram antes realizadas na esfera privada foram transferidas da casa para o setor público.

A necessidade de trabalhadores qualificados no setor de assistência social e de saúde (caring sector) e a profissionalização do trabalho com crianças e jovens criaram novas oportunidades para as meninas. Essas mulheres são treinadas para toda uma gama de profissões relacionadas a cuidados sociais e de saúde no segundo ciclo da escola secundária profissional, com dois anos na escola e dois anos como aprendiz. A unidade e a diversidade estão deixando uma marca nesse campo. Odesenvolvimento pessoal que é parte da educação para a indústria e para os ofícios difere muito de acordo com o ofício, sejam os ofícios da construção civil, do trabalho nos estaleiros, gráficas ou açougues. $\mathrm{O}$ novo setor de serviços, que treina jovens para trabalhar em jardins de infância, hospitais e lares de idosos, tem a tradição de aprendizagem na prática, em comum com o treinamento para os ofícios e a indústria. Porém, esse treinamento também tem outras dimensões. Nos ofícios relacionados aos cuidados de saúde e sociais as relações sociais são centrais; isso significa treinamento para o relacionamento com outros seres humanos - crianças nas creches, pacientes nos hospitais ou pessoas idosas nos lares de idosos.

Neste artigo, começo a analisar formas de tratar a unidade e a diversidade do desenvolvimento curricular na didática profissional em diferentes campos da educação profissional, dos ofícios tradicionais e das indústrias ao setor de serviços, que cresce 
rapidamente. Analisarei como enfocar a questão para entender melhor a unidade e a diversidade no campo do desenvolvimento curricular profissional, na medida em que se relaciona com as mudanças da tecnologia e dos processos de trabalho. Também discutirei a diversidade em diferentes campos, como treinamento dos socorristas e auxiliares de enfermagem, levando em conta o debate sobre o aprendizado em escolas profissionalizantes e a aprendizagem no local do trabalho. Começo apresentando as últimas reformas no segundo ciclo da educação secundária na Noruega e, depois, analisarei essa questão complexa.

\section{As RECENTES REFormas EDUCACIONAIS NA NorUEgA}

As relações no segundo ciclo da educação secundária entre trabalho e educação, aprendizado no trabalho e nas escolas e educação profissional e educação geral foram os aspectos centrais das recentes reformas educacionais na Noruega. A aprendizagem nos locais de trabalho, que nas décadas de 1960 e 1970 foi considerada por muitos como uma relíquia do passado, recuperou sua importância vital. Durante a época otimista dos anos 1970, as intenções políticas democráticas eram de abolir a Lei do Aprendiz em favor de incorporar toda a educação profissionalizante ao sistema escolar, integrando as escolas técnicas aos ginásios, no mesmo marco legal. Uma legislação comum para toda a educação secundária foi implementada no dia $1^{\circ}$ de janeiro de 1976, integrando todas as escolas para os estudantes na faixa etária entre 16 e 19 anos. $^{2}$ Essa foi uma integração de todos os tipos anteriores de escolas, que refletiam as divisões de classe da sociedade. Um dos objetivos fundamentais da nova legislação era conseguir a igualdade entre educação prática e teórica. Os velhos ginásios e as escolas profissionalizantes ficariam sob o mesmo teto, e os processos de aprendizagem que forneciam mão de obra barata, marcada pela exploração, seriam substituídos pela educação profissional dentro do sistema escolar.

Esse dois processos se mostraram desafiadores e problemáticos. Pode-se afirmar que nas primeiras décadas seguintes à nova lei o sistema escolar continuou como antes, com a escola secundária preparando para a educação superior e a educação profissional preparando para o trabalho qualificado e semiqualificado no mercado de trabalho. Ao mesmo tempo, a questão da qualificação da força de trabalho era discutida em nível mais alto do que nunca. A tecnologia da informação modificou os processos de trabalho na maioria dos ofícios. As profissões de cuidados sociais e com a saúde (caring professions) desenvolveram uma plataforma para o segundo ciclo da educação secundária e novas formas de aprendizagem prática. Nas últimas décadas surgiram mudanças consideráveis na organização do trabalho e novos desafios para os sistemas educacionais em geral e, especificamente, para a educação profissional.

\section{O IMPACTO DA REFORMA DE 1994}

A "Reforma 94" foi a lei aprovada pelo Parlamento norueguês em 1994 que reformou a educação profissional, de modo que

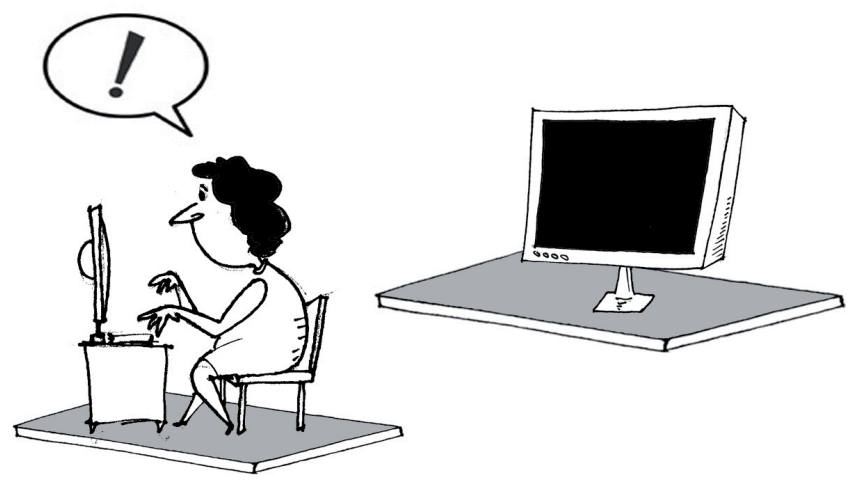

agora são necessários dois anos de escola seguidos de dois anos de aprendizagem no trabalho. O sistema dual, que combina o aprendizado numa situação escolar e numa escola profissional, passa por um renascimento, porém numa forma mais eficiente (Mjelde, 1993). ${ }^{3}$ Esse sistema foi agora expandido para novas áreas e ofícios. Mais de 180 ofícios estão incluídos na Lei da Aprendizagem no Local de Trabalho.

Reformas adicionais foram implementadas durante o outono de 2006, sendo chamadas de kunnskapsloftett, o que significa elevar o nível de conhecimento (Relatório Branco No 30, 2003-2004). ${ }^{4}$ Diminuiu-se o número de horas passadas em oficinas, padarias, oficinas mecânicas, etc., onde se aprende na prática, e aumentou-se o trabalho acadêmico na sala de aula. Todos os cursos teóricos são dados na escola durante os primeiros dois anos. As antigas escolas de aprendizes, frequentadas à noite ou num único dia da semana, foram abolidas. Foi fechado o caminho de se obter um certificado de ofício entrando diretamente num programa de aprendizagem após a escolaridade obrigatória. ${ }^{5}$

\section{A TRANSIÇÃo DA ECONOMIA INDUSTRIAL PARA A DE SERVIÇOS}

Os velhos ginásios e a educação profissionalizante tinham raízes muito diferentes na sociedade (ver também Koski, em seu livro) $)^{6}$ : os ginásios vinham das velhas "escolas de catedrais", e a educação profissional das tradições feudais de aprendizagem mestre-aprendiz. A educação profissional em escolas surgiu com a industrialização. A meta e a essência dessa forma de educação consistem no aprendizado para o trabalho (Mjelde 1987, 1993, 2006) ${ }^{7}$. A principal arena de aprendizado nas escolas profissionais é o trabalho prático, feito em oficinas e laboratórios. Os professores eram recrutados no mercado de trabalho. $\mathrm{Na}$ tradição do aprendizado acadêmico, a vida na escola e a vida no trabalho eram separadas. Na educação profissional, as atividades da "vida real" eram as oficinas: cozinhas, oficinas de engenharia mecânica, laboratórios fotográficos, etc. As vocações baseadas no trabalho, como as especializações industriais, empregos comerciais e de escritório, trabalhos nos setores agrícola e marítimo, assim como as tradições do artesanato doméstico e da economia doméstica, estiveram no centro da educação profissional norueguesa. $\mathrm{O}$ aspecto especial dessa transição é a ligação entre os campos profissionais e as atividades produtivas do país. Velhos ofícios 
desaparecem e novos surgem. As mudanças nos processos de trabalho mostram constantemente a necessidade de uma força de trabalho qualificada. A educação profissional está mudando continuamente, junto com as mudanças na produção.

Vimos uma transição da economia industrial para uma economia de serviços nos países escandinavos, assim como no restante do mundo. Ofícios tradicionalmente masculinos desapareceram, e novos ofícios abertos às mulheres sofreram modificações. Novos ofícios são incluídos em processos de aprendizagem, e novos desafios e contradições surgem no sistema educacional tanto na escola quanto no local de trabalho. Matérias técnicas (ensino nas oficinas e teoria dos ofícios), por um lado, e matérias gerais, por outro, têm uma história longa e complexa no desenvolvimento da educação profissional no sistema escolar. Hoje em dia os desafios estão em nível ainda mais alto. Pode-se indagar se o velho método taylorista de organizar a força de trabalho na produção está sendo contestado, se o desenvolvimento tecnológico em geral muda os processos de trabalho de forma a questionar a divisão tradicional do conhecimento - a divisão entre trabalho intelectual e manual - e a divisão entre as tradições de aprendizado acadêmico e aprendizado profissional em nossa parte do mundo. As novas reformas introduziram questões novas em torno da aprendizagem em oficinas e o aprendizado nas escolas ${ }^{8}$ (ver também Hardig, 1995; Hedmann, 2001). ${ }^{\text {? }}$

\section{A essência da pedagogia da formação profissional é a aprendizagem na oficina e na situação do trabalbo. Não é o \\ ensino, mas o aprendizado que está no centro da didática da educação profissional.}

Neste artigo vou analisar como podemos realizar trabalho empírico para compreender a unidade e a diversidade no campo da pedagogia profissional: quais são os processos específicos de aprendizado que são comuns ao treinamento dos engenheiros mecânicos, técnicos de informática ou auxiliares de enfermagem, todos os quais passaram por dois anos como estudantes na escola e dois anos como aprendizes, antes de integrarem a força de trabalho qualificada da Noruega? Quais são as similaridades e diferenças entre os programas educacionais? Uma coisa eles têm em comum: o fato de as próprias atividades do trabalho serem o ponto focal do aprendizado (Sannerud, 2005). ${ }^{10}$ Esta é a essência da didática do ensino profissionalizante. $\mathrm{Na}$ Escandinávia, um dos maiores estudiosos nesse campo é Lennart Nilsson. Tratarei de seu trabalho antes de prosseguir discutindo sobre como analisar mais detalhadamente a unidade e a diversidade no complexo campo da educação profissional.

\section{DIDÁTICA DA EDUCAÇÃO PROFISSIONAL: O APRENDIZADO GIRA EM TORNO DA ATIVIDADE DO TRABALHO}

Os conceitos de pedagogia da educação profissional e didática da educação profissional são novos no campo dos estudos educacionais. A essência da pedagogia da formação profissional é a aprendizagem na oficina e na situação do trabalho. Não é o ensino, mas o aprendizado que está no centro da didática da educação profissional (Nilsson 2004) ${ }^{11}$. Nilsson ${ }^{12}$ argumenta que para entender o que cria uma boa situação de aprendizado para os estudantes, como os problemas do ensino surgem e se modificam para os professores e como ocorre o progresso, deve-se estudar mais do que o conteúdo do ensino. É necessário também estudar como o ensino é distribuído e transformado na prática do cotidiano dos docentes e alunos. É preciso investigar como os estudantes e os professores veem o conteúdo concreto do ensino e o que é considerado significativo nesse conteúdo, na perspectiva atual tanto dos estudantes quanto dos professores (Nilsson 1986). ${ }^{13}$ Há muito pouca pesquisa na Escandinávia sobre educação profissional em geral, e é especialmente escassa a pesquisa focada na vida cotidiana de alunos e professores. ${ }^{14}$

São exceções as importantes investigações empíricas de Nilsson sobre a aprendizagem em oficinas na Suécia, na década de 1970 (Nilsson 1985,1986, 1998, 2004). ${ }^{15}$ Foram realizadas pesquisas baseadas em problemas para compreender por que surgem dificuldades de aprendizado entre os alunos e quais são os problemas dos professores, numa situação em que $20 \%$ dos estudantes abandonavam a escola. Estudos preliminares indicam que a maioria dos estudantes queria tarefas escolares que tivessem aplicações concretas. Muitos estudantes reclamavam que o trabalho escolar que faziam e o aprendizado pelo qual haviam passado eram totalmente sem sentido. O que, então, os estudantes considerariam significativo e importante? Em que perspectiva temporal os alunos pensavam e agiam? Havia pontos de vista diferentes entre os estudantes de uma mesma classe? Uma das coisas que Nilsson descobriu foi que aquilo que o aluno considerava significativo dependia da relação concreta entre a natureza da tarefa e a perspectiva de tempo que o estudante tinha em mente. Estudantes da mesma classe ou nível tinham perspectivas temporais altamente diversas. A não ser por acaso, o aluno era incapaz de encontrar significado em seu próprio trabalho escolar. Caso as tarefas estivessem limitadas ao que podia ser realizado no intervalo de atenção do aluno e este sentisse que havia obtido êxito na tarefa, então crescia a amplitude do conhecimento e a profundidade da concentração em relação ao intervalo de atenção dedicado à tarefa. O sucesso em pequenas tarefas de curta duração possibilitava que o indivíduo se envol- 
vesse em projetos maiores, que consumiam mais tempo. Este resultado oferece novos insights sobre o que constitui relevância ou significação e as condições que afetam o progresso do aprendizado. Estas são perspectivas importantes para levar em conta, ao tentar compreender as tarefas mais complexas encontradas na preparação para o aprendizado em todas as situações de ensino (ver também Grimestad, 1993). ${ }^{16}$

Significado e motivação são dois lados da mesma moeda nos processos de aprendizado (Enerstvedt 1987; Mjelde 1993; Mjelde 2005). ${ }^{17}$ Regi Enerstvedt assinala que o propósito de todo o processo de aprendizado é a preparação para algo distinto. Para muitos, o aprendizado escolar é a preparação para se incorporar à força de trabalho. Ele prossegue afirmando que um dos principais problemas é a distância entre a escola e o trabalho. O aumento das horas passadas no ensino convencional em sala de aula, afastado da vida prática do trabalho, é um dos principais problemas das reformas escolares atuais. Um dos problemas principais da Reforma 94 é a redução dos campos profissionais e da aprendizagem no local de trabalho no primeiro ano de estudos, juntamente com o aumento para dois anos do período de frequência à escola antes que o aluno possa postular o aprendizado de um ofício. Felizmente, o interesse em realizar trabalho empírico nesse campo complexo é maior do que nunca (Mjelde; Daly, 2006). ${ }^{18}$

Pode-se dizer que até agora o problema tem sido a dificuldade epistemológica de integrar conhecimento prático e conhecimento acadêmico. Em outras palavras, expressar-se nos processos de ensino e aprendizado na forma específica das tradições de educação para a classe trabalhadora e a educação profissional (ver também Luria, 1976; Mjelde, 1987,1990). ${ }^{19}$ No entanto, estamos agora vendo trabalhos empíricos sobre os diferentes ofícios, e esses trabalhos nos fazem levantar novas questões no debate geral no campo dos estudos de educação.

\section{DidÁTICA DA EDUCAÇão PROFISSIONAL DO PONTO DE VISTA DOS ASPECTOS ESPECIAIS DOS VÁRIOS OFÍCIOS}

A unidade e a diversidade são as marcas registradas da pedagogia da educação profissional. A unidade é encontrada na didática da educação profissional, que toma como seu ponto de partida a própria atividade como o locus da aprendizagem. Ela também reconhece a necessidade de conhecimentos gerais em relação às operações do trabalho prático e às tradições cooperativas da aprendizagem, que são essenciais nessas tradições de aprendizado. A diversidade está nas necessidades diferentes dos distintos ofícios por processos de trabalho diversos e também na diversidade do uso da tecnologia da informação nos diferentes ofícios. Por exemplo, na área dos cabeleireiros o aprendizado virtual está sendo utilizado para demonstrar estilos de corte de cabelo aos clientes (Sund, 2006). ${ }^{20}$ Nos ofícios da construção civil, há uma focalização constante no trabalho em equipe e na prestação de contas, porque o computador exige uma visão geral de todo o processo de construção (Mjelde; Daly, 2006; Sannerud, 2005). ${ }^{21}$ Monitores e câmeras são instalados nos caminhões, de modo que os motoristas podem se informar sobre tudo, das condições meteorológicas às placas de sinalização das estradas, porém podem também ser observados e seguidos em todos os estágios de suas viagens (Brynhillsvoll, 2007). ${ }^{22}$ No entanto, a aprendizagem prática é naturalmente o aspecto central dos processos de aprendizado de todos os ofícios e profissões.

Nas décadas recentes, a revolução da tecnologia da informação e comunicação (TIC) trouxe mudanças consideráveis para a organização do trabalho e novos desafios para os sistemas educacionais. Por um lado, as TIC surgem como promessas para educare empoderar as sociedades, e foram amplamente promovidas como ferramentas indispensáveis no aprendizado e na vida econômica e social. Por outro lado, uma ampla representação de cientistas sociais tem observado os aspectos informacionais, científicos e tecnológicos associados à construção das sociedades da "informação" ou do "conhecimento"; ou seja, sociedades com fluxos de informação em expansão, facilitados por sistemas similares de organização do trabalho, são dimensões cruciais de qualquer projeto de crescimento socioeconômico de longo prazo. No entanto, a revolução das TIC também criou novas demandas de treinamento para a força de trabalho, assim como novas oportunidades para os alunos.

\section{O QUE CONSTITUI VARIAÇÕES DE COMPETÊNCIA E APRENDIZADO NA EDUCAÇÃO E NO TREINAMENTO PROFISSIONAL?}

A questão das habilidades do mercado de trabalho tem se mostrado complexa, e deflagrou um intenso debate acadêmico durante as últimas décadas. Esse problema está diretamente relacionado ao desenvolvimento da educação e da aprendizagem profissional na era industrial (Mjelde 1997). ${ }^{23}$ A revolução 
das TIC desafia as divisões dentro do conhecimento em geral e também dentro de ofícios e profissões específicas. Novos estudos empíricos na Escandinávia têm mostrado, em toda sua complexidade, as variações na aprendizagem nos locais de trabalho e nas escolas, assim como os novos desafios tanto nos locais de trabalho quanto nos sistemas escolares, na educação e no treinamento profissional. O trabalho empírico de Ronny Sannerud (2005) ${ }^{24}$ a partir dos locais da construção civil estava ligado a como esses trabalhadores imaginavam o local ideal (ou ótimo) para sua aprendizagem e seu desenvolvimento pessoal. Ele descreveu a situação da seguinte forma: a antiga relação primária entre aprendiz e colegas e mestre/professor foi agora ampliada para incluir novos métodos tecnológicos de aprendizado, como bases de dados, livros eletrônicos, apresentações multimídia, assim como o uso do e-mail e da Internet para acessar mais informações. Grete Haaland Sund (2006) ${ }^{25}$ mostra desafios diferentes no desenvolvimento do treinamento no campo dos salões de beleza. A profissão de cabeleireiro tem base local e uma forte ênfase de mercado na escolha do consumidor; isso significa que se espera do cabeleireiro conhecer um grande número de estilos de corte de cabelo. O desejo específico de cada cliente precisa ser discutido e atendido. Nenhum cliente é igual ao outro. As notícias sobre novos estilos de corte de cabelo se espalham rapidamente na Internet, e os monitores são ferramentas úteis.

Vibe Aarkrog (2006) ${ }^{26}$ e Faizul Bhyat (2006) ${ }^{27}$ realizaram seu trabalho empírico, respectivamente, entre socorristas na Dinamarca e operadores de máquinas de litografia na África do Sul, levantando questões básicas para o difícil problema da divisão social do conhecimento na educação profissional. Aarkrog analisou a transferência de conhecimentos da sala de aula para o local de trabalho no treinamento e na educação de socorristas na Dinamarca, que são treinados tanto como mecânicos quanto como paramédicos. Um dos principais problemas é saber o que os aprendizes acham que necessitam para sua complexa vida

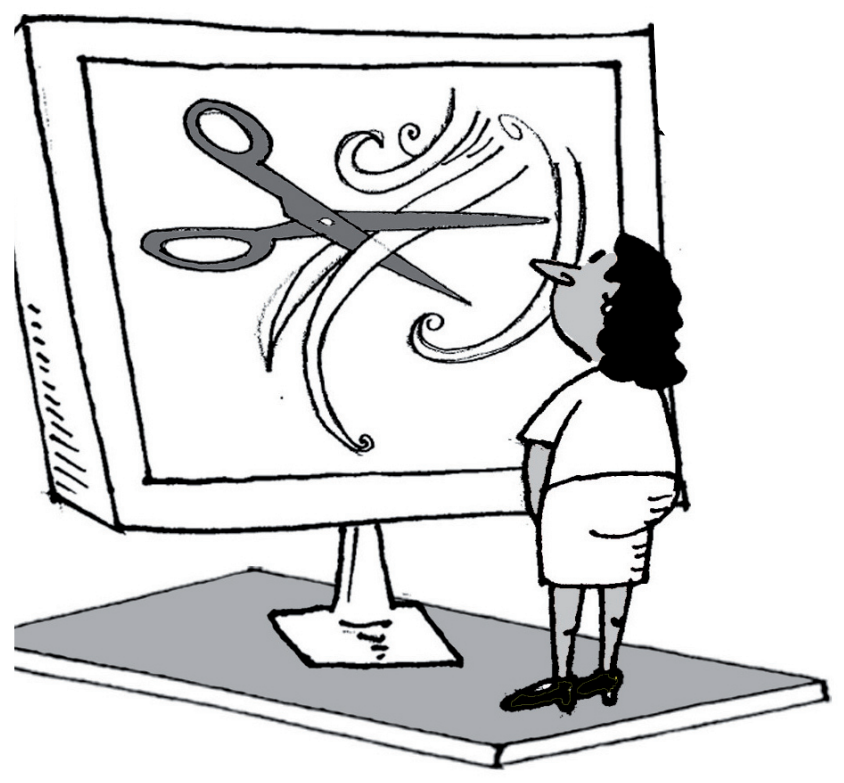

de trabalho, ou seja, como se relaciona na prática o currículo escolar com as tensas situações emergenciais do trabalho? Os trabalhadores que atuam em situações de emergência percebem que a maior parte das falhas mecânicas não passa de incidentes simples, na maioria das vezes solucionáveis com a repetição e a aplicação de conhecimentos formais. Entretanto, consideram que as situações envolvendo a interação humana são problemáticas e mais complexas. A escola e suas competências técnicas pareciam mais remotas para o estudante quando este estava envolvido no socorro a pessoas e em situações de emergência. Quando os acidentes incluem vítimas humanas, os estudantes têm de lidar com fatores não instrumentais, como emoção, dor, estresse e morte, enquanto aplicam seu julgamento profissional e procedimentos aprendidos. Em emergências humanas onde há ameaça à vida o conhecimento transferido está sujeito à interpretação, algo que contesta seriamente a educação e o treinamento baseados na escola (ver também Thatt-Jensen 2002). ${ }^{28}$

No desenvolvimento da educação e do treinamento profissional nas escolas também tivemos uma divisão entre a aprendizagem na oficina/teoria profissional e as disciplinas escolares gerais/acadêmicas. Durante todo um século essas divisões criaram situações de aprendizado desfavoráveis para a classe trabalhadora. Bhyat (2006) ${ }^{29}$ tem buscado novas formas de transcender essas contradições (ver também Bongo, 1999; Mjelde, 2006). ${ }^{30}$ Bhyat tem trabalhado coletivamente com trabalhadores jovens, tentando extrair princípios científicos gerais da operação cotidiana de máquinas. Ele descreve a experiência de ensinar alguns princípios de matemática, física e química a aprendizes da operação de máquinas de litografia. Sua meta foi "extrapolar" de detalhes da prática para generalizações da teoria com os aprendizes, trabalhando em conjunto com um engenheiro e um mestre de ofício. Ele descreve o processo de identificar e ensinar alguns princípios de física, observáveis na situação de trabalho, a operadores de máquinas.

Kari Kravik (2004) ${ }^{31}$ analisou as estratégias de aprendizado na escola e no trabalho para o treinamento de auxiliares de enfermagem, uma profissão caracterizada pela necessidade de compreender a interação humana. A prática dos cuidados é parte importante do treinamento dos auxiliares de enfermagem. A profissão exige conhecimento da natureza humana e o desejo e a capacidade de ver a situação do "outro". Nas novas profissões na área dos cuidados sociais e de saúde existe uma clara dimensão orientada para o "outro", que vai desenvolver a capacidade e o desejo do estudante de se identificar com a situação de vida de outras pessoas e avaliar como lidar com relações sociais no seu trabalho cotidiano. As habilidades de comunicação, cuidado e cooperação são essenciais para o currículo. Essas habilidades são consideradas qualificações-chave para sua identidade como auxiliares de enfermagem. Isso está no centro do desafio das novas profissões relacionadas à expansão do setor de serviços. Os estudantes do setor de hospitalidade têm suas cozinhas, ao passo que os estudantes de mecânica têm suas oficinas mecânicas. Porém, no setor de cuidados sociais e de saúde é mais difícil criar boas situações de aprendizado no sistema escolar porque é difícil trazer pacientes e crianças para as salas de aula (Waale, 
2008). ${ }^{32}$ Assim, um treinamento realista e relacionado à práxis no sistema escolar pode ser um grande desafio. Os estudantes têm "períodos de prática" em locais de trabalho durante os primeiros dois anos, antes que comecem sua aprendizagem. Os professores supervisionam e cooperam com os orientadores dos locais de trabalho. Os professores dizem que os estudantes aprendem melhor essas habilidades no trabalho prático, junto com outros estudantes (Kravik, 2004). ${ }^{33}$ Porém, o problema de significação e motivação no contexto de sala de aula no setor de cuidados sociais e saúde está se mostrando um grande desafio para os professores (Waale, 2008). ${ }^{34}$

Ida Juul (2005) analisou uma outra dimensão desse problema. Após estudar o paradigma de acesso igual à educação superior para os filhos dos trabalhadores, ela concluiu que o resultado não intencional dessa política tinha sido reforçar a crença amplamente difundida de que as habilidades intelectuais gerais eram superiores às habilidades práticas e relacionadas ao trabalho (ver também Kokkersvold; Mjelde,1982). ${ }^{35}$ Esses pressupostos são parte da divisão entre trabalho intelectual e manual, e essa divisão enfrenta novos desafios hoje em dia com o desenvolvimento das novas tecnologias. Ela também descobriu que os aprendizes preferem a aprendizagem no local de trabalho à educação baseada na escola. Isso é consistente com os resultados de meus próprios estudos entre aprendizes na Noruega na década de 1980. De 1.619 aprendizes entrevistados em cinco cidades diferentes, 1.438, ou $89 \%$, preferiam aprender numa situação de trabalho do que na escola. A atração do "trabalho prático", "fazer algo real", "ser pago por isso" e "ter bons companheiros de trabalho" foram razões citadas pelos aprendizes para descrever suas experiências contrastantes no trabalho e na escola (Mjelde, 1993, 2006). ${ }^{36}$ Porém, o motivo não é que as oportunidades de aprendizagem sejam melhores no local de trabalho do que nas escolas profissionais (Mjelde, 1990). ${ }^{37}$ A razão é que os estudantes preferem o processo de estar numa situação de trabalho real ao processo de aprendizado na escola, que não tem nenhum significado para eles. Jens Wilbrandt $(2002)^{38}$ resume seu trabalho empírico com aprendizes dinamarqueses ao enfatizar a necessidade de focar na relação entre aprendizagem no local de trabalho e os processos gerais de aprendizado. Os processos de aprendizagem dos aprendizes devem ser o foco, e cada indivíduo deve ser encontrado onde está (ver Nilsson, acima). As relações sociais do local de trabalho são de grande importância para o bemestar e o processo de amadurecimento de cada indivíduo. Cem aprendizes, de um total de 1.617 do Projeto de Aprendizagem (1982-1984), tinham críticas a suas experiências como aprendizes nos locais de trabalho. Suas situações de trabalho não eram boas situações de aprendizagem. No entanto, a maioria deles se sentia mais útil, mais livre fazendo parte do mundo adulto e do "mundo do trabalho real". Embora a maior parte dos aprendizes expresse sua satisfação por ter conseguido um posto, seu prazer era medido em relação a algo diferente. Era a experiência do contraste entre o mundo sem sentido e muitas vezes doloroso da escola e uma situação na qual ganhavam dinheiro e se sentiam úteis que fazia com que esses jovens preferissem ser aprendizes (Mjelde 1990). ${ }^{39}$ As perspectivas de tempo também têm sua importância. Eles sabem que a aprendizagem termina dentro de um ou dois anos.

Para resumir, os novos ofícios e a tecnologia da informação cumprem papéis diferentes dentro do vasto campo da educação profissional, e um dos principais aspectos de projetos futuros deve ser realizar estudos de caso comparativos dentro de diferentes setores, para entender como o desenvolvimento está afetando os processos de trabalho e de aprendizado dentro de cada campo específico. O conceito de "aprendizado na práxis" e como passar dessa práxis para o conhecimento mais geral constitui o problema central, assim como o conteúdo desse conhecimento geral. Como, no entanto, a unidade e a diversidade se manifestam nos diferentes campos? Quais são as similaridades e diferenças entre trabalho e aprendizado nos diferentes campos? Quais são os desafios da aprendizagem na prática quando lidamos com máquinas e quando lidamos com seres humanos, ou então quando tratamos com ambos? É um desafio clarificar como estratégias de aprendizado diferentes são necessárias para diferentes processos de trabalho relacionados a condições econômicas e sociais distintas. A realização de estudos de caso cuidadosos em nível local pode fornecer a base necessária para uma administração e um planejamento mais bem informados do futuro aprendizado socioeconômico e educacional em níveis individual, local, macrorregional e nacional. Hoje em dia, como nunca antes, o conhecimento didático fundamental e operativo da educação profissional está fazendo avançar a aprendizagem profissional e o desenvolvimento da identidade profissional (Nilsson, 2004; Mjelde, 2006). ${ }^{40}$ Além disso, temos uma maior compreensão de como os seres humanos aprendem por meio da atividade, que é um aspecto central da didática da educação profissional. A questão do significado e da motivação nos proces-

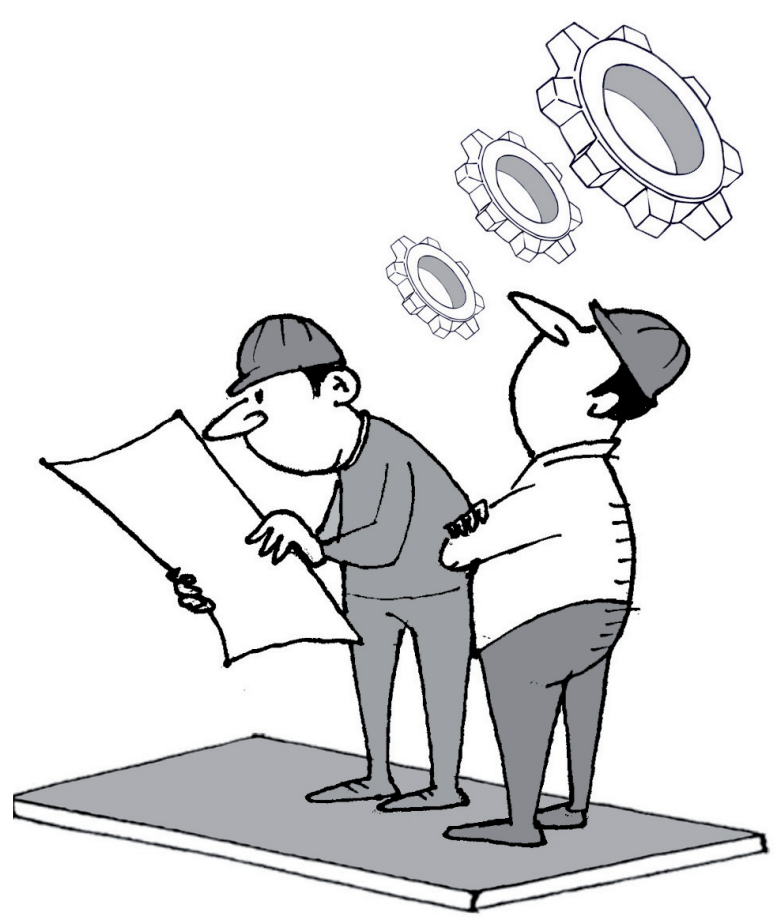


sos de aprendizado é da maior importância para a compreensão desse problema (Mjelde, 1993, 2006). ${ }^{41}$

\section{CoNCLUSÃo}

Há vinte anos os tópicos do conhecimento prático, da educação profissional e da aprendizagem no trabalho não estavam na agenda pública, nem tampouco no campo acadêmico da educação. Eram questões excluídas da história da educação, da pedagogia e da sociologia da educação (Heikkinen; Sultana, 1997). ${ }^{42}$ Os debates educacionais gerais prosseguiam na Noruega como se não houvesse um mercado de trabalho, a educação dos trabalhadores, a educação profissional e a aprendizagem no trabalho. Isso mudou durante a atual crise. O ensino escolar e seu afastamento da vida do trabalho são agora questões centrais na discussão da educação acadêmica e da educação profissional. Isso colocou a classe trabalhadora e a educação profissional na agenda científica de uma nova maneira. Manfred Wahle (2003) ${ }^{43}$ esboça um novo programa para estudos históricos do século XX, e partes daquela pesquisa são uma fonte importante, inclusive para a história da educação profissional. A pesquisa histórica é necessária para a autocompreensão da educação profissional e do treinamento, tanto como área disciplinar quanto como conhecimento pedagógico. Pesquisas sobre as histórias de vida das pessoas nesta época de expansão do sistema educacional têm também produzido uma compreensão mais profunda do efeito da educação na vida das pessoas (Goodson, 2000; Antikainen $e t$ al., 1999, Antikainen, 2002). ${ }^{44} \mathrm{Um}$ entendimento da organização total do trabalho e das dinâmicas de gênero, classe e etnicidade tem dimensões importantes para as futuras pesquisas sobre a complexidade das relações dos seres humanos com o trabalho e com a educação (Lakes, 1997; Gonon et al., 2001; Husemann; Heikkinen, 2003; Lakes; Carter, 2004). ${ }^{45}$

Aclarar as contradições que surgem nos currículos dos ofícios no segundo ciclo da escola secundária não é negar que alguns são melhores do que os outros. É importante apresentar uma compreensão dos dois lados dessa atividade humana, tanto a tradição prática da oficina quanto o caminho da educação geral acadêmica. Ambos devem ser levados em conta, porém de forma a se enriquecerem mutuamente. Atualmente há quase uma hegemonia dos modelos de aprendizado acadêmico que refletem as tradições de aprendizado da elite do poder e desconsidera as ricas e significativas tradições de aprendizagem originadas do trabalho produtivo (ver também Kraus, 2004; Koski, 2003; Lindgren, 2004). ${ }^{46}$ Porém, essas contradições podem também ser úteis na medida em que sejam analisadas de forma aberta e simples e, assim, tornadas conscientes e compreensíveis. O entendimento dessas contradições poderá contribuir para a democratização mais ampla da escola e da educação em geral. A reflexão crítica das ciências sociais e as abordagens interdisciplinares do aprendizado trazem esperanças de uma compreensão mais profunda desses fenômenos, abrindo alternativas a modos de pensar executivos e administrativos que atualmente têm quase um controle hegemônico no campo da educação.

\section{A pesquisa bistórica é necessária} para a autocompreensão da educação profissional e do treinamento, tanto como área disciplinar quanto como conbecimento pedagógico. Pesquisas sobre as histórias de vida das pessoas nesta época de expansão do sistema educacional têm também produzido uma compreensão mais
profunda do efeito da educação
na vida das pessoas.

\section{Notas}

MJELDE, L. The magical properties of workshop learning. Bern: Peter Lang, 2006.

2 A Lei de 21 de junho de 1974 sobre o Segundo Ciclo da Educação Secundária. A educação na Noruega ainda é essencialmente pública. Há poucas escolas privadas. As leis e políticas que regem o sistema educacional norueguês são criadas por decisões do Parlamento. Por exemplo, antes da integração as escolas profissionais e os ginásios eram regidos por legislações distintas.

3 MJELDE, L. Apprenticeship: from practice to theory and back again. Joensuu: University of Joensuu Press, 1993.

${ }^{4} \mathrm{O}$ mesmo parece estar ocorrendo na Suécia e na Finlândia em relação à educação profissional e a de adultos. A educação profissional e a de adultos são dois lados da mesma moeda. White Paper n ${ }^{\circ} 30$ (2003-2004), Kultur for loering. Oslo: Ministry of Education and Research.

5 Isso é uma questão contestada e em negociação. Porém, esse problema não faz parte de meus argumentos neste documento.

${ }^{6}$ KOSKI, L. Female entrepreneurs in the learning society. In: HUSEMANN, R.; HEIKKINEN, A. (Eds) Governance and marketisation in vocational and continuing education. Frankfurt am Main: Peter Lang, 2004. p. 4964.

MJELDE, L. From hand to mind. In: LIVINGSTONE, D. (Ed) Critical pedagogy and cultural power. Mass.: Bergin \& Garvey Publishers,1987; Id.(1993) op. cit.; Id.(2006) op. cit.

8 Não estou afirmando que o taylorismo está morto, especialmente não no novo setor de serviços, porém está assumindo novas formas em relação aos novos processos de trabalho.

9 HARDIG, J. Att utbilda fill arbefare. En studie av gymnasieskolans bygg och anloeggstekniska linje och yrkesloererare. (Dissertation) Lund University, Institute of Pedagogy, 1995; HEDMANN, A. I nationens och det praktiska 
livets tjoenst. Det svenska yrkes-skolesysremets tillkomst och utveckling 1918 till 1940. (Dissertation) . Umea University, Institute of Pedagogy, 2001.

${ }^{10}$ SANNERUD, R. Learning at the construction site: utopia of reality. (Dissertation) Roskilde: Universidade de Roskilde, 2005.

${ }^{11}$ NILSSON, L. Nordisk yrkespedagogikk i internationellt perspektiv. Nordiske yrkesperlagogiske konferanse. Reykjavik, Kennaraha-skoli Islands, 2004. Paper presented to the 19 .

${ }^{12}$ Id. ibid.

${ }^{13}$ NILSSON, L. Fackdidaktik ur yrkespedagogiskt perspektiv. In: MARTON, F. (Ed) Fackdidaktik Dei I. Lund: Akademieforlaget, 1986.

${ }^{14}$ Porém, em anos mais recentes temos visto um crescente interesse em pesquisar no campo da educação profissional na Noruega. Podemos encontrar inspiração importante em alguns trabalhos internacionais. A Alemanha tem uma tradição forte em Berufspadagogik. Ronald Sultana, da Universidade de Malta, realizou um grande projeto de pesquisa empírica sobre a educação profissional em Malta. SULTANA, R. Educationa1 and National Development. Historical and critical perspectives on vocational educational in Malta. Malta: Minerva Publications,1992. Claude Grignon, L'ordre des choses. Paris: Ed. de Minuit, 1971, realizou um projeto na França há mais de três décadas. $\mathrm{O}$ trabalho de Jeanne Gamble sobre a pedagogia dos ofícios manuais é uma nova e importante contribuição (SULTANA, R. Educational and National Development. Historical and critical perspectives on vocational educational in Malta. Malta: Minerva Publications,1992.) (GAMBLE, J. Tacir knowledge in crafi pedagogy. (Dissertation). Cape Town: University of Cape Town, 2004, ver também BHYAT, F. From the particularities of practice to the generalisation of theory. In: MJELDE, L.; DALY, R. (Eds.) Working knowledge in a globalizing world. Bern: Peter Lang, p. 39-60, 2006. A pesquisa de acompanhamento da Reforma 94 na Noruega também fez avançar a compreensão desse campo (OLSEN et al. Fagopploering i omforming. Evaluering av Rcform 94. Sluttrapport. Bergen: AHS-serien, 1998; OLSEN, O. J. (Ed) Yrkesutdanning og fagopploering under en moderniserings-offensiv. Opplegg for evaluering av Refonn 94. Bergen: AHS-serien, 1996;OLSEN, O. J. The firm as a place of learning in vocational education. Results from the studies of Norwegian VET. In: HUSEMANN, R.; HEIKKINEN, A. (Eds) Governance and marketization in vocational and continuing education. Frankfurt am Main, Peter Lang, p. 177-190, 2004; A Dinamarca conduz trabalhos empíricos que farão avançar ainda mais nossa compreensão (NIELSEN, K.; KVALE, S. (Eds) Mesterloere. Loering som sosial praksis. Oslo: Ad Notam Gyldendal, 1999; Id. Prakrikkens Loeringslandskap. At loere gjennom arbeide. Kobenhavn: Akademisk forlag, 2003;WILBRANDT, J. (2002) Vekseluddannelse $i$ handverkuddannelser. Loerlinges opploering, faglighed og identitet. Copenhagen, Ministry of Education, 2002. uddannelsessty-relsen temahaefteserie nr. 14; THATT-JENSEN, L. Mellon and og hand. En empirisk analyse af hvordan loerlinge loerer mellom skole og praktikk $i$ de danske erhversuddannelser. Arhus: University of Arhus, 2002; JUUL, I. Pa sporet af erhervspedagogikken. Om baggrunnen for erhvewsuddannelsernes aktuelle utformning og smede og industritekniker mode med vekseluddannelssystemet. (Dissertation) Copenhagen: Institute of Pedagogical Sociology, The Pedagogical University of Denmark, 2005; AARKROG, V. Apprentices transfer of knowledge from school to work place in the VET Dual System: a study of a VET-Programme for Rescue Officers. In: MJELDE, L.; DALY, R. (Eds.) Working knowledge in a globalizing world. Bern: Peter Lang, 2006. p. 25-39.

${ }^{15}$ NILSSON, L. Perspektiv pâ yrkesloerande i skolmassig form. Kapittel 1 i Fornyelse av yrkeslarande. Paper. Institute of Pedagogy Goteborg, University of Goteborg, 1985; Id. (1986) op. cit.; Id. Utmaningar fran det yrkesdidaktiska foeltet Conference report. Hogskolen i Akershus, Nordisk yrkespedagogisk konferanse, 1998; Id. Nordisk yrkespedagogikk i internationellt perspektiv. Nordiske yrkesperlagogiske konferanse. Reykjavik, Kennaraha-skoli Islands, 2004. Paper presented to the 19.
${ }^{16}$ GRIMESTAD, V. Om bakgrunn og prestasjoner: elever med grunnlag i forkurs mekaniske fags utvikling med hensyn ti1 trivsel, motivasjon og sosial integrering i loeremessig sammenheng. (Thesis) Oslo: SYH, 1993.

${ }^{17}$ ENERSTVEDT, R. Virksomhef og mening. Utvklingen av loeremotivasjon hos norske skolebarn. Institute of Sociology, University of Oslo, 1987. p. 3. Manuscript; MJELDE, Liv. (1993) op. cit., p. 104-122; Id. In search of learning and meaning in vocational education. In: SABOUR, M.; KOSKI, L. (Eds). Searching for the meaning of education and culture. Joensuu: University of Joensuu Press, 2005.

${ }^{18}$ MJELDE, L.; DALY, R. (Eds) Workiiig knowledge in a globalizing world. Bern: Peter Lang, 2006. p. 25-39.

${ }^{19}$ LURIA, A.R. Cognitive development: its cultural and social foundations. Cambridge Ma: Harvard University Press, 1976; MJELDE, L. (1987) op. cit.; Id. Labour and learning: the apprenticeship program in Norway. Interchange, v.21, n.4, p. 34-48, 1990.

${ }^{20}$ SUND, G. H. Forskjelligliet og mangfold-muligheter eller begrernsninger for individ og arbeidsplass? Et aksjonsforskningsprosjekt med studier av loering $\mathrm{i}$ daglig arbeid, gjennom medvirkning, demokratiske prosesser og interesse-differensiering. (Dissertation) Roskilde: Roskilde University, 2006.

${ }^{21}$ MJELDE, L.; DALY, R. (Eds) (2006) op. cit.; SANNERUD, R. (2005) op.cit.

${ }^{22}$ BRYNHILLSVOLL, R. Yrkessjaforens nye utfordinger med EU-direktivne. (Master thesis). Kjeller: HIAK, 2007.

${ }^{23}$ MJELDE, L. The promise of alternative pedagogies: the case of workshop learning. In: WATSON, K. et al. (Eds) Educational dilemmas: debate and diversity. London: Cassells, 1997

${ }^{24}$ SANNERUD, R. (2005) op. cit.

${ }^{25}$ SUND, G. H. (2006) op. cit.

${ }^{26}$ AARKROG, V. (2006) op. cit.

${ }^{27}$ BHYAT, F. (2006) op. cit.

${ }^{28}$ THATT-JENSEN (2002) op. cit.

${ }^{29}$ BHYAT, F. (2006) op. cit.

${ }^{30}$ BONGO, M. Yrkesrettet voksenopploering i en reforrntid. (Master thesis). Akershus: Hogskolen i Akershus, 1999; MJELDE, L. (2006) op. cit.

${ }^{31}$ KRAVIK, K. Undervisning som passer som hand $\mathrm{i}$ hanske med yrkesopploeringen og elevgruppen. (Master thesis). Kjeller: HIAK, 2004.

32 WAALE, M. Rolle, identitet og undervisningspraksis i den videregaende skolen: en kvalitativ studie. (Dissertation). Tromso: University of Tromso, 2008.

${ }^{33}$ KRAVIK, K (2004) op. cit., p. 72.

${ }^{34}$ WAALE,M. (2008) op. cit.

${ }^{35}$ KOKKERSVOLD E.; MJELDE, L. Yrkesskolen som forsvan. Oslo: Gyldendal, 1982.

${ }^{36}$ MJELDE, L (1993) op. cit.; Id. (2006) op. cit.

${ }^{37}$ Id. (2009) op. cit..

${ }^{38}$ WILBRANDT, J. (2002) op. cit.

${ }^{39}$ MJELDE, L. (1990) op. cit., p. 41-43.

${ }^{40}$ NILSSON, L. (2004) op. cit.; MJELDE, L. The magical properties of workshop learning. Bern: Peter Lang, 2006.

${ }^{41}$ MJELDE, L. (1993) op. cit..; Id. (2006) op. cit. 
${ }^{42}$ HEIKKENEN, A. ; SULTANA, R. Vocational education and apprenticeships in Europe. Challenges for practice and research. Tampere: University of Tampere press, 1997.

${ }^{43}$ WAHLE, M. New challenges in history of vocational education. In: CONFERENCE OF THE VET \& CULTURE NETWORK "OCCUPATION AND EDUCATION IN TRANSITION", 10th. Mustiala 12 at15 June, 2003. Paper.

${ }^{44}$ GOODSON, I. Livshistorier; kilde til forstaelse av utanning. Bergen: Fagbok- forlaget, 2000; ANTIKAINEN, A., et al. Construction of Identity and Culture through Education. International Journal of Contemporary Sociology, 36, p. 204-228, 1999; ANTIKAINEN, A. Identity and learning in a Nordic information society. In: KUNZEL, K. (Ed) Internationales Jahrbuch der Erwachsenenbildung. Band 30. Allgemeinbildung zwischen Postmodern und Burgergesellschaft. Koln: Bohlau, p. 21-31, 2002.

${ }^{45}$ LAKES, R. The new vocationalism. Deweyan, Marxist and Freirian themes.Columbus: Ohio, Center on Education for Training and Improvement, The Ohio State University, 1997; GONON, P. et al. Gender perspectives on vocational education. Bern: Peter Lang, 2001; HUSEMANN, R.; HEIKKINEN, A. Governance and marketisation in vocational and continuing education. Frankfurt am Main, Peter Lang, 2004); LAKES, R.; CARTER, P. Globalizing education for work. Comparative perspectives on gender and the new economy. Mahwah, New Jersey: Lawrence Erbaum Associates, 2004.

${ }^{46}$ KRAUS, K. New "virtues of employees", a topic for educational science. In: LINDGREN, A.; HEIKKINEN, A. (Eds) Social competences in vocational and continuing education. Bern: Peter Lang, 2004. p. 215-226; KOSKI, L. (2004) op. cit, LINDGREN, A. Can research on vocational education and training (VET) still be progressive? In: LINDGREN, A.; HEIKKINEN, A. (Eds) Social competences in vocational and continuing education. Bern: Peter Lang, 2004. p. 17-41.

\section{ABSTRACT}

Liv Mjelde. The experience of vocational education in Norway.

"Vocational pedagogy" and "vocational didactics" are new concepts that have been developed in relation to an understanding of teaching and learning processes to which workshop learning and learning in working life are central. Vocational pedagogy is a learner-centered approach to teaching and learning, in which the relation between the student and the task is central; the work activity itself is the fulcrum for learning. In this paper I start to explore ways of seeing the unity and variations in curriculum development in vocational didactics brought about by the changes in technology and developments in the labor market and in vocational education. I also discuss the core challenge of moving from learning in praxis to general knowledge in a variety of vocational fields in which learning in schools is contrasted to learning in the field.

Keywords: Vocational Education; Vocational pedagogy; Educational reforms; Norway.

\section{RESUMEN}

Liv Mjelde. La experiencia de la educación profesional en Noruega.

"Pedagogia de la formación profesional" y "didáctica de la formación profesional" son nuevos conceptos que se han desarrollado con relación a una comprensión de los procesos de enseñanza y aprendizaje para los cuales son centrales el aprendizaje en talleres y en la vida laboral. La "pedagogia de la formación profesional" es un enfoque de la enseñanza y del aprendizaje centrado en el alumno. En este enfoque resulta central la relación entre el alumno y la tarea a realizar. La tarea en si misma es el punto de inflexión para el aprendizaje. En este trabajo comienzo explorando las distintas maneras de ver la unidad y las variaciones que han provocado los cambios de tecnología en el desarrollo del programa de "didáctica de la formación profesional" $y$, asimismo, los adelantos surgidos en el mercado del trabajo y en la educación profesional. También expongo el desafio profundo que significa pasar del aprendizaje en la praxis al conocimiento general en una variedad de áreas profesionales en los cuales el aprendizaje en las escuelas se contrapone al aprendizaje en el campo de trabajo.

Palabras clave:Educación Profesional; Pedagogia de la Formación Profesional; Reforma de la Educación; Noruega. 